\title{
Psychological distress, perceived social support, and television viewing for reasons of companionship: A test of the compensation hypothesis in a population of crime victims
}

JURGEN MINNEBO

\section{Abstract}

Becoming a crime victim is often associated with the development of psychological distress symptoms. In turn, these symptoms have been found to be related to a decrease in perceived social support by the victim. From a uses and gratifications point of view, the increase in distress and the decrease in perceived social support could well affect a victim's television use. Furthermore, the compensation hypothesis (Davis and Kraus, 1989) proposes that people with little social contact use mass media to compensate for social isolation. It could therefore be hypothesized that increased use of television for reasons of companionship is related to higher levels of psychological distress and lower levels of perceived social support. The present study used a structural equation model to test this hypothesis. The sample consisted of 212 Flemish victims of crime. The results confirm the proposed relationships and hypotheses. Directions for future research are discussed.

Keywords: crime victims, perceived social support, psychological distress, television, uses and gratifications

\section{Introduction}

Becoming a crime victim is often an overwhelming experience that may have a serious impact on the victim's life and beliefs. As a consequence, most crime victims experience symptoms of psychological distress in the days, weeks, and even months following the victimization experience (Denkers and Winkel, 1998; Frieze, Hymer, and Greenberg, 1987; Harrison and Kinner, 1998; Kamphuis and Emmelkamp, 1998). It is hypothesized in the present study that the development of psychological distress symptoms following criminal victimization may have an influence on the victim's television use. The uses and gratifications perspective in particu- 
lar lends theoretical support to this claim as it proposes both psychological and social factors as origins of media use. First, psychological distress may well have an impact on a crime victim's exposure to television and some studies have found depression to be related to specific patterns of television use (Dittmar, 1994; Kleinke, 1988; Potts and Sanchez, 1994). Second, previous research indicates that psychological distress symptoms such as depression are related to the erosion of actual and perceived social support (Lepore, Evans, and Schneider, 1991; Quittner, Glueckauf, and Jackson, 1990; Yap and Devilly, 2004), leaving crime victims socially isolated. The compensation hypothesis, which is rooted in the uses and gratifications theory, predicts that victims may then turn to television to compensate for this social deprivation (Davis and Kraus, 1989).

The aim of the present research, then, is to provide an in-depth study of the relationship between psychological distress, perceived social support, and television use for reasons of companionship.

\section{Psychological distress as a result of criminal victimization}

According to Janoff-Bulman (1989, 1992), a person holds three fundamental assumptions about the world: a) The world is a place where good events outweigh bad ones; b) each individual has control over what happens to him/her, and c) the self is worthy. These assumptions lead us to believe that we all have a 'unique invulnerability' to criminal victimization: It is possible that other people fall victim to assault, rape, or robbery, but the chance of it happening to us personally seems rather small (Janoff-Bulman, 1989, 1992; L. S. Perloff, 1983). When becoming a crime victim, this feeling of invulnerability and the fundamental assumptions it stems from are rudely shattered (Denkers and Winkel, 1998; Fischer and Wertz, 1979; Frieze and Bookwala, 1996; Frieze, Greenberg, and Hymer, 1987; Janoff-Bulman, 1989, 1992). Victims experience that events may get out of their control and that human interactions are sometimes based on predator versus prey relationships, causing confusion and uncertainty (Denkers and Winkel, 1998; Fischer and Wertz, 1979; Janoff-Bulman, 1989). As a result, most crime victims display symptoms of psychological distress (Creamer, Burgess, Buckingham, and Pattison, 1993; Norris and Kaniasty, 1994). Some of these symptoms reflect the disruption of the aforementioned fundamental assumptions. Since a crime victim can no longer unconditionally assume that the world is essentially 'good', feelings of distrust and hostility towards other people may arise. Furthermore, the intentional violation of the self by the perpetrator may cause the victim to doubt his or her self-esteem, giving rise to moodiness and feelings of depression. Previous studies have 
indeed reported an increase in psychological disturbances such as hostility, moodiness, depression, and distrust of others across research populations of victims of rape, (aggravated) assault, robbery, and property crime (Bard and Sangrey, 1986; Creamer et al., 1993; Frieze et al., 1987; Gabor and Normandeau, 1989; Hanson, Kilpatrick, Falsetti, and Resnick, 1995; Kamphuis and Emmelkamp, 1998; Krupnick, 1980; Leymann, 1985).

\section{A conceptualization of social support}

A factor that has consistently been found to reduce the severity of psychological distress symptoms following criminal victimization is social support (Frieze et al., 1987). Social support is a valuable resource for crime victims, since it provides them with both material and psychological assistance in dealing with the aftermath of the traumatic experience (Frieze and Bookwala, 1996; Frieze et al., 1987). Hobfoll (1988: 121) defines social support as "those social interactions or relationships that provide individuals with actual assistance or that embed individuals within a social system believed to provide love, caring, or sense of attachment to a valued social group or dyad". From this definition it becomes clear that the social support concept consists of two separate dimensions: Received social support refers to the help an individual has actually received, whereas perceived social support reflects the perceived availability of support in times of need (Barrera, 1986; Norris and Kaniasty, 1996; Yap and Devilly, 2004). Almost all research has consistently reported that perceived social support is related more strongly to distress symptoms than received social support (Cohen and Wills, 1985; Helgeson, 1993; Norris and Kaniasty, 1996). An explanation for this finding is that, even though provided social support may be well-intended by the support giver, victims often find it unhelpful because the offered support is not in their best interest (e.g., Wortman and Lehman, 1985; Herbert and Dunkel-Schetter, 1992). Therefore, the concept of perceived social support is considered more valuable and important than received social support (Cohen, Mermelstein, Kamarck, and Hoberman, 1985; Norris and Kaniasty, 1996), and will be used in this study as well.

Perceived social support (PSS) is in itself a multidimensional concept, since different needs require different support resources. A much used typology (e.g., Cohen et al., 1985; Crane and Constantino, 2003; Finn and Gorr, 1988; Kaniasty and Norris, 1992; Turner-Cobb, Sephton, Koopman, Blake-Mortimer, and Spiegel, 2000) proposed by Cohen and Hoberman (1983) discerns four categories of support functions: 'Appraisal support' or the availability of someone to talk to about one's problems; 'belonging support' or the availability of people with whom 
one can do things; 'tangible support' or instrumental/material aid, and 'self-esteem support' or the availability of a positive perception of the self when comparing oneself with others. This typology is also highly relevant for victims of crime, since previous research has indicated that crime victims experience beneficial effects when being able to draw on all four types of social support (e.g., Coates, Wortman, and Abbey, 1979; Frieze and Bookwala, 1996; Wethington and Kessler, 1986).

\section{The relationship between psychological distress and perceived social support}

As already mentioned, perceived social support is presumed to provide a buffer against the severity of psychological distress (Cohen and Wills, 1985; Peirce, Frone, Russel, Cooper, and Muddar, 2000; Regehr, Hemsworth, and Hill, 2001). Paradoxically, however, it is precisely in times when social support is needed most that it may become less available (Frieze et al., 1987; Herbert and Dunkel-Schetter, 1992; Wortman and Lehman, 1985; Yap and Devilly, 2004). Previous research has indicated that crime victims are at risk of becoming socially isolated as people may avoid them because they tend to see victims as responsible for their victimization, consider them to be losers, or generally feel uncomfortable in their vicinity (Bard and Sangrey, 1986; Coates et al., 1979; Herbert and Dunkel-Schetter, 1992; Lerner, 1970; Silver, Wortman, and Crofton, 1990). Furthermore, becoming a crime victim may instill feelings of hostility and distrust towards other people, which may hamper the victim's willingness and ability to reach out for help while at the same time driving possible support providers away. Finally, since typical depressive symptoms include feelings of loneliness and worthlessness, a victim's depressed mood may in itself be responsible for a decrease in perceived social support. Thus, distress symptoms such as depression, hostility, and distrust of other people may erode a victim's social support resources, both actual and perceived.

Consequently, the causal direction of the relationship between (P)SS and symptoms of psychological distress has been reconsidered. Longitudinal research has indicated that apart from mitigating distress, both actual and perceived social support are negatively affected by stressors as well (Lepore et al., 1991; Mahon and Yarcheski, 2001; Mohr, Classen, and Barrera, 2004; Quittner et al., 1990; Yap and Devilly, 2004). In summary, it can be hypothesized that the intensity of distress symptoms in victims of crime may lead to a decrease in levels of perceived social support. Therefore $\mathrm{H} 1$ stipulates:

H1: An inverse relationship exists between levels of psychological distress and perceived social support. 


\section{Uses and gratifications theory, psychological distress, and perceived social support}

As the previous paragraphs indicate, a crime victim may experience some radical changes in his or her life. The months following the victimization experience are often dominated by trying to come to terms with what has happened, fighting distress symptoms such as fear, depression, distrust of and hostility towards other people. Furthermore, just as victims need all the support they can get to deal with these difficulties, it may become less available, both in reality and in the perception of the victim.

It is in this context of dramatic changes that an everyday activity such as watching television may change as well. Especially the theoretical premises of the uses and gratifications theory seem to offer support for this thesis, since they propose that the needs people try to fulfill by watching television have psychological and social origins (Katz et al., 1974; McQuail, 1997). In the present context this implies that victims a) suffering from psychological distress and $b$ ) perceiving a decrease in social contact expect specific gratifications from watching television. In fact, there is empirical support for both parts of this assumption.

First, previous research has found a typical distress symptom such as depression to be related to 'ritualistic' (Rubin, 1984) patterns of television use. In a sample of college students, Perloff, Quarles, and Drutz (1983) found a direct and significant impact of depression on television viewing to escape from problems. Especially relevant is Potts and Sanchez's study (1994) which measured depression in a normal student population and found higher levels of depression in both male and female students to be correlated positively with television viewing 'to avoid loneliness'. In the present context, our second hypothesis can thus be formulated as follows:

$\mathrm{H}$ 2: Psychological distress is related positively to the ritualistic television viewing motive 'companionship viewing'.

Second, with regard to social deprivation, the compensation hypothesis predicts that people who become socially isolated will try to substitute interpersonal contact with media use. Applied to television, this substitution supposedly takes the form of an increase in both amount of television use and specific use of television for reasons of social compensation (Davis and Kraus, 1989). Empirical tests of this hypothesis have produced mixed results, however. With regard to the predicted relationship between social impoverishment and amount of television viewing in particular, there is little research that substantiates the hypothesis; only occasionally has evidence been presented that is in line with the expectations (Perlman, Gerson, and Spinner, 1978). Meanwhile most studies 


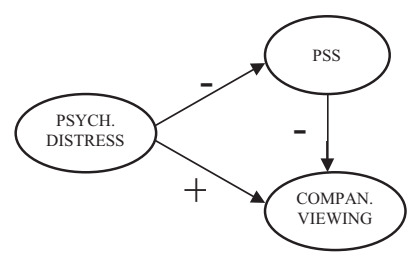

Figure 1. Hypothesized model: Psychological distress and perceived social support as determinants of companionship viewing.

report only insignificant relationships (e.g., Austin, 1985; Davis and Kraus, 1989; Hoover, Skuja, and Cosper, 1979). Attempts to link social isolation to television viewing motives have been more successful. Perloff et al. (1983) reported positive relationships between dissatisfaction with interpersonal relationships and parasocial interaction with television. Other (though somewhat weak) relationships have been found between loneliness and reliance on television (Rubin, Perse, and Powel, 1985). Finally, and most relevant for the present study, Finn and Gorr (1988) found an inverse relationship between perceived social support and television viewing for reasons of social compensation. Thus, as predicted by the compensation hypothesis (Davis and Kraus, 1989) and in line with the results reported by Finn and Gorr (1988), a negative relationship is expected between levels of perceived social support and television viewing for reasons of companionship:

H3: Perceived social support is related inversely to television viewing for reasons of companionship.

In summary, it is expected that increasing levels of depression, distrust, and hostility in crime victims inspire the belief that less social support resources are available. As a reaction, victims turn to television to compensate (at least partially) for this lack of support. These relationships can be graphically represented as above.

\section{Method}

\section{Subjects}

Subjects for this study were 212 recent victims of crime, aged twelve or older, who were contacted by the national Victim Support Unit between October 2002 and July $2003^{1}$. Within three months after this contact, the victim received a paper-and-pencil self-report questionnaire. Subjects reported having become a victim of a wide range of crimes from at- 
tempted murder to burglary ${ }^{2}$. The victims in the sample were predominantly female $(75.5 \%)$, resembling previous research in victim populations (e. g., Wirtz and Harrell, 1987), and were on average 40.7 years old $(S D: 16.5)$. Respondents' highest completed level of education were: No education or only grade school $(17.5 \%)$; the first three years of high school $(22.8 \%)$; high school $(40.3 \%)$, and three or four years of college education $(21.3 \%)$.

\section{Measures}

Psychological distress. To measure psychological distress, the depression, distrust, and hostility subscales of the Dutch version of the Symptoms Check List-90 (SCL-90; Arrindell and Ettema, 1986) were used. Respondents indicated on a five-point scale ranging from 1 (not at all) to 5 (very serious) to what extent they suffered from forty complaints typically associated with depression (sixteen items), distrust and interpersonal sensitivity (eighteen items), and hostility (six items). Respondents indicated the presence of the complaints since their victimization experience. As can be seen from the sample items ${ }^{3}$, these subscales are very relevant to the possible erosion of perceived social support.

Perceived social support. The twelve-item version of the Interpersonal Support Evaluation List (ISEL-12) was used for this study. This scale, which is a shortened version of the 40-item ISEL (Cohen et al, 1985; Cohen and Hoberman, 1983), measures three dimensions of perceived social support: Appraisal support (e.g., "When I need suggestions on how to deal with a personal problem, I know someone I can turn to"), belonging support (e.g., "If I wanted to have lunch with someone, I could easily find someone to join me"), and tangible support (e. g., "If I were sick, I could easily find someone to help me with my daily chores"). The meaning of these dimensions was discussed earlier. Each dimension was measured by four items. Respondents indicated on a four-point scale ranging from 1 (totally disagree) to 4 (totally agree) to what extent they judged twelve statements to apply to themselves. Half of the items were positive statements about social relationships, while half were negative statements. The negatively phrased statements were subsequently reverse-coded to calculate overall scores for each dimension of PSS. Thus, for each ISEL-subscale higher scores indicate higher levels of perceived appraisal support, belonging support, or tangible support.

Television viewing for reasons of companionship. The three-item 'companionship' viewing subscale from the television viewing motives scale developed by Rubin $(1981,1983)$ was used for this study. The items read "I 
watch television to feel less lonely", "I watch television so I am not alone", and "I watch television when there's no one else to talk to". Respondents indicated to what extent they thought each motive applied to them: 1) Never true for me; 2) occasionally true for me; 3) often true for me; 4) most of the time true for me, or 5) always true for me.

Demographics. Three socio-demographic variables were assessed: Gender, age, and educational level. Educational level was measured using an eleven-point scale ranging from "I did not complete any education" to "I hold a four year college degree".

\section{Results}

\section{Measurement}

Means, standard deviations and - if applicable - Cronbach alpha coefficients for the depression, distrust, hostility, perceived social support, and companionship viewing scales are reported in Table 1. The depression, distrust, hostility, appraisal support, and companionship measures show moderately high to high internal consistency. The alpha values of the depression, distrust, and hostility subscales equal or exceed the values found during the psychometric testing of the scales (Arrindell and Ettema, 1986). The Cronbach alpha value for the tangible support subscale is fairly low. Initially, the same problem was encountered with the belonging subscale $(a=.56)$. However, a re-analysis of the item-total correlations of this subscale indicated a problematic item ${ }^{4}$. After removing this item from the scale, the alpha value increased to an acceptable .69. Consequently, the item was deleted from the belonging subscale for all further analyses.

As expected, the psychological distress levels found in this sample are far higher than 'normal'. Taking the norm scores found in a normal population as a reference, the distress levels of the men in this sample can be ranked 'high', while the scores of the women can be ranked 'high' and 'very high'. In general, the distress levels reported here resemble those found in phobic people (Arrindell and Ettema, 1986).

Furthermore, Table 1 lists the results of t-tests comparing men and women for all variables used in the present study, and Pearson zeroorder correlation coefficients to assess the association between these variables and age and educational level. With the exception of the correlation between gender and hostility, all demographic variables are related significantly to psychological distress, with women displaying higher levels of distress, as do younger respondents and subjects with a lower 
Table 1. Means, standard deviations, and Cronbach alpha coefficients for distress symptoms, television viewing motives, television affinity and amount of television exposure; $t$-values for mean differences between men and women; Pearson zeroorder correlations between age, educational level and distress symptoms.

\begin{tabular}{lrrrrrrr}
\hline Measures & Mean SD & $\begin{array}{l}\text { Cr. } \\
\text { Alpha }\end{array}$ & $\begin{array}{l}\text { Score } \\
\text { Range }\end{array}$ & t-values & $\begin{array}{l}\mathrm{r} \text { with } \\
\text { age }\end{array}$ & $\begin{array}{l}\mathrm{r} \text { with } \\
\text { educa- } \\
\text { tion }\end{array}$ \\
\hline SCL-90 depression & 39.2 & 16.8 & .94 & $16-80$ & $-4.16^{* *}$ & $-.20^{* *}$ & $-.28^{* *}$ \\
SCL-90 distrust & 37.4 & 15.5 & .92 & $18-90$ & $-2.09^{*}$ & $-.16^{*}$ & $-.28^{* *}$ \\
SCL-90 hostility & 10.8 & 5.2 & .84 & $6-30$ & -1.61 & $-.31^{* *}$ & $-.20^{* *}$ \\
ISEL-12 'appraisal' & 12.1 & 2.5 & .72 & $4-16$ & -.35 & -.09 & $.23^{* *}$ \\
ISEL-12 'belonging' & 8.7 & 2.1 & .69 & $3-12$ & .34 & -.12 & $.25^{* *}$ \\
ISEL-12 'tangible' & 12.0 & 2.3 & .55 & $4-16$ & .33 & -.12 & $.18^{* *}$ \\
Companionship viewing & .92 & 1.0 & .81 & $0-4$ & -1.58 & .02 & $-.24^{* *}$ \\
\hline
\end{tabular}

Note. ${ }^{*} \mathrm{p} \leq .05{ }^{* *} \mathrm{p} \leq .01$

educational level. However, only educational level is associated with perceived social support and television viewing for reasons of companionship, with more highly educated respondents showing more perceived social support and less inclination to watch television for reasons of companionship.

\section{Hypotheses}

In order to adequately test the theoretical model proposed in Figure 1, a structural equation model (SEM) was estimated. The concepts included were psychological distress as measured by depression, distrust, and hostility, the three PSS-subscales, and companionship viewing. Only educational level was included as a socio-demographic variable, since the results presented in Table 1 indicate it is correlated with psychological distress, PSS, and companionship viewing, whereas age and gender are only related to (some) distress levels.

The model thus comprised four constructs and ten measurement variables. The construct 'education' was treated as an exogenous variable, the constructs 'psychological distress' and 'PSS' as intermediate endogenous variables, and the construct 'companionship viewing' as an endogenous variable. The measurement model of psychological distress comprised the depression, distrust, and hostility subscales of the SCL-90. Likewise, the measurement model of PSS consisted of the three subscales 'appraisal support', 'belonging support', and 'tangible support'. Companionship viewing was measured by the three manifest items used in the questionnaire.

The specification of the paths from the exogenous construct educational level to the other constructs was based on the initial bivariate 


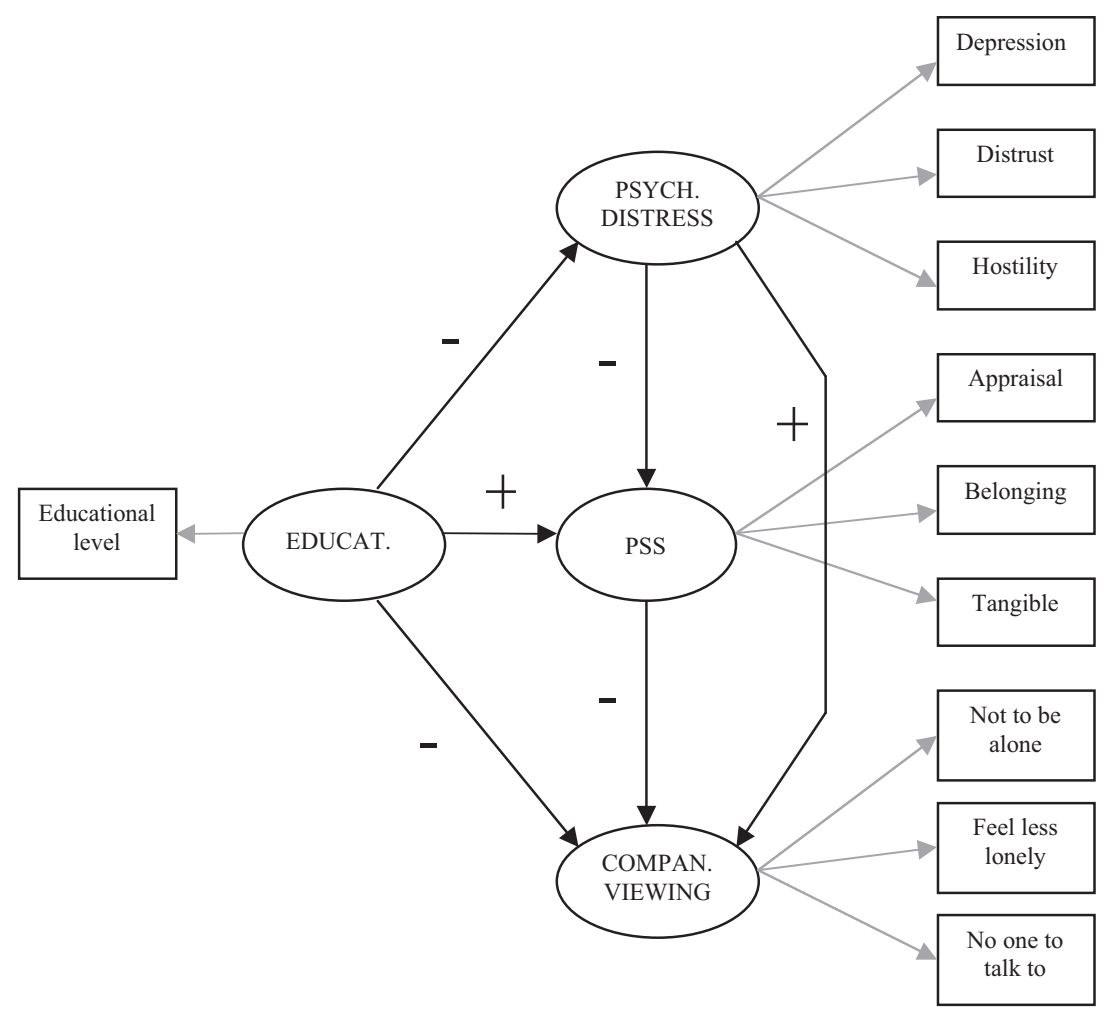

Figure 2. Hypothesized SEM-model: Educational level, psychological distress and perceived social support as determinants of companionship viewing.

correlation coefficients reported in Table 1. Thus, we expected negative paths from educational level to psychological distress and companionship viewing, and a positive path from educational level to PSS. The paths between psychological distress, PSS, and companionship viewing reflect those presented in Figure 1. We predicted negative paths from psychological distress to PSS and from PSS to companionship viewing. Finally, we expected a positive path from psychological distress to companionship viewing. Figure 2 represents the hypothesized structural and measurement model.

Using LISREL $8.50^{\circledR}$ this model was fitted to the covariance matrix with the maximum-likelihood estimation method. Even though the overall fit of the initial model was good $\left(X^{2}=38.34, d f=30, p=.14\right)$, the results indicated that the direct path from educational level to companionship viewing was non-significant, possibly because educational level 


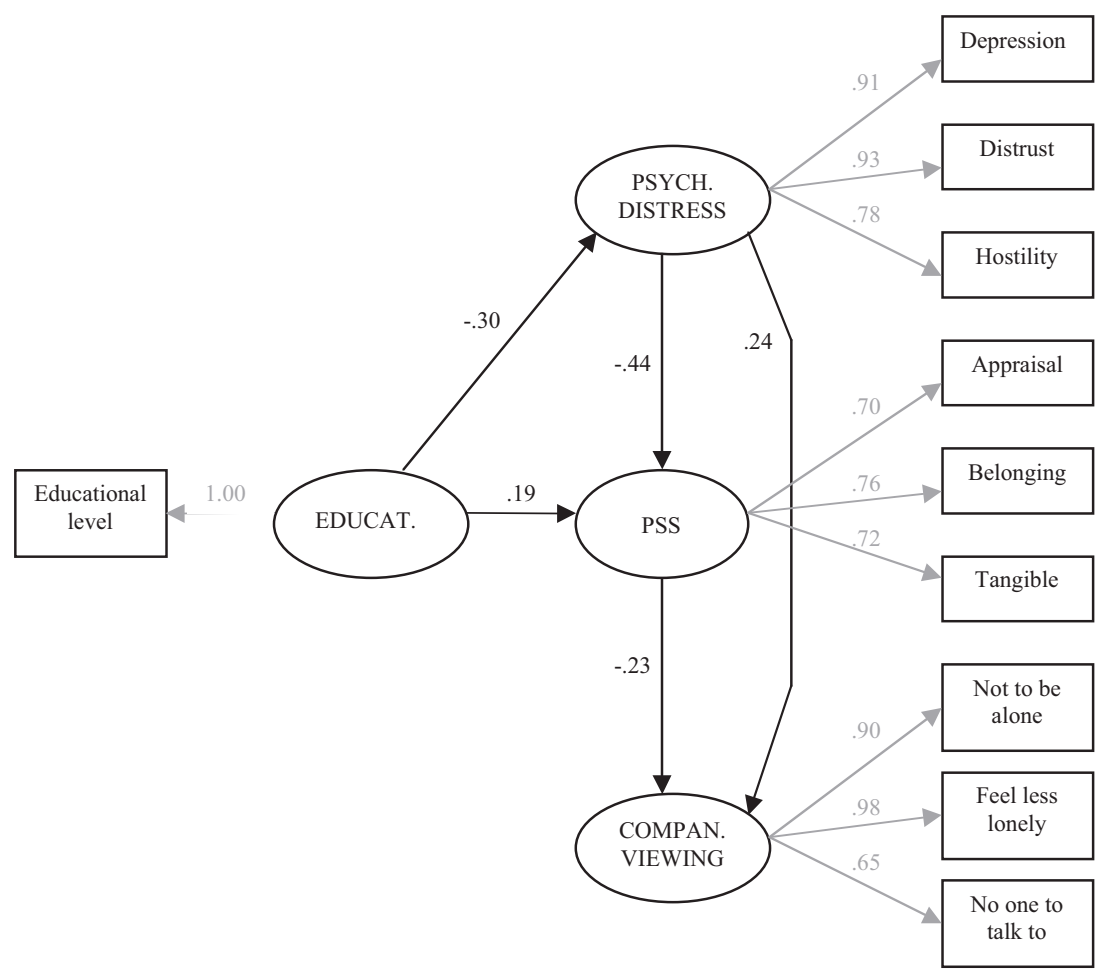

$X^{2}=41.32, d f=31, P=.10195, R M S E A=0.045, G F I=.95, A G F I=0.91$

Figure 3. Respecified SEM-model - standardized: Educational level, psychological distress and perceived social support as determinants of companionship viewing.

was already indirectly related to companionship viewing through distress and PSS. Furthermore, the path from PSS to companionship viewing was only marginally significant $(t=-1.80)$. Following the recommendation made by Aish en Jöreskog (1990) that only paths with significant $\mathrm{t}$-values should be included in the final model, the non-significant path from educational level to companionship viewing was removed first. The modified model was then retested. The results of this analysis are reported in Figure 3.

The overall fit of the respecified model was good $\left(X^{2}=41.32, d f=\right.$ $31, p=.10)$. Furthermore, both the Goodness of Fit Index $(G F I=.95)$ and Adjusted Goodness of Fit Index $(A G F I=.91)$ indicated a good fit. Finally, since $R M S E A$-values lower than .05 indicate a good fit and values up to .08 a reasonable fit (Browne and Cudeck, 1993), the redefined 
model meets this criterion as well, with an RMSEA-value of .045 and a 90 percent confidence interval of $0.0<R M S E A<0.078$. Furthermore, all paths are significant and in line with the hypothesized model.

\section{Discussion}

The aim of the present article was to study the relationship between psychological distress, perceived social support, and television use for reasons of companionship. More specifically, it was hypothesized that typical distress symptoms following criminal victimization erode perceived social support, resulting in turn in more use of television for reasons of social compensation.

The results found in this study lend support to all of the hypotheses postulated. First, the negative path from psychological distress to PSS indicates that crime victims hold the opinion that less support is available to them as levels of depression, distrust, and hostility towards others increase. Second, in line with previous studies inspired by the uses and gratifications theory (Potts and Sanchez, 1994), the model shows a positive relationship between distress levels and television viewing for reasons of companionship. Third, the results lend support to that part of the compensation hypothesis that predicts the substitution of interpersonal contact by television use for reasons of social compensation in times of increased social isolation. The construct PSS as measured by all three of its dimensions (appraisal, belonging, and tangible) predicts television viewing for reasons of companionship, with higher levels of PSS resulting in less companionship viewing. In summary, the results of this study indicate that increasing levels of depression, distrust, and hostility in crime victims inspire the belief that less social support resources are available. In reaction, victims use television to compensate at least partially for this perceived lack of support. As such, the present study lends strong support to the claim of the uses and gratifications theory that both social and psychological antecedents predict specific television use.

A remarkable result is the role of educational level in the SEM-model. Educational level was only indirectly related to companionship viewing through distress levels and PSS. Previous research has repeatedly found that socioeconomic status (SES) has an impact on media use (e.g., Roe, 2000; Roe, Eggermont, and Minnebo, 2001); the significant paths from educational level to distress and PSS and the non-significant path to companionship viewing apparently suggest that SES is first and foremost related to the psychological antecedents that structure media use. As such, these results are in line with previous research reporting a buffering effect of higher SES on the severity of distress symptoms (Dohrenwend, 
1978; Geckova, van Dijk, Stewart, Groothoff, and Post, 2003; Gibbs, 1980; Gleser, Green, and Winget, 1981) and erosion of social support (Geckova et al., 2003).

Nevertheless, a number of caveats should be borne in mind. More specifically, there are some remarks to be made regarding the measurement of PSS. First, to keep the questionnaire length within acceptable limits, we used the twelve-item version of the ISEL-40; this shortened version measures only three dimensions of PSS, excluding self-esteem support. Even though this may to some extent prevent the confounding of the depression subscale with the self-esteem dimension from PSS, this fact obstructs the systematic analysis of the PSS concept in relationship to psychological distress and television use. Second, the psychometric properties of the ISEL-12 are unknown. As demonstrated above, only the appraisal subscale showed acceptable reliability in its original form. The belonging subscale only approximated an alpha of .70 after one item was excluded from the scale; the tangible subscale had an alpha of only .55. Apart from possible weaknesses in the design of the ISEL-12, the possibility that the Dutch translation had an effect on the consistency of the scale cannot be discarded either.

The present research used a theory-based approach to predict the direction of the relationships in this study. First, the uses and gratification theory explicitly postulates that viewing motives have psychological and social origins (Katz et al., 1974; McQuail, 1997). Given the specific psychological profile of the sample used in this study, it was thus hypothesized that distress symptoms originate more companionship viewing. Likewise, levels of perceived social support were considered social origins of television use, thus leading to the hypothesis that PSS predicted companionship viewing. Finally, based on recent research results (e. g., Mahon and Yarcheski, 2001; Mohr et al., 2004; Yap and Devilly, 2004), we hypothesized that PSS may be influenced by distress levels, even though there is also research evidence indicating that distress levels are mitigated by PSS. As such, the model presented here is explicitly theorydriven, which is in fact the only way to define SEM-models in crosssectional data.

This does not imply, however, that the inverse relationships are improbable, especially when studying the present topic over time. As such, we believe testing a number of these inverse relationships in a longitudinal design is an important suggestion for further research. First, the current findings suggest that television viewing for reasons of companionship offers victims a viable and immediately available alternative for 'real life' company when perceived interpersonal support is deemed insufficient. Consequently, an important question is the effectiveness of companionship viewing with regard to the lessening of the impact of 
perceived social deprivation. Can companionship viewing indeed provide companionship for people feeling socially isolated? Since television viewing is traditionally considered a substitute for interpersonal contact (Kraus and Davis, 1989; Finn and Gorr, 1988; Canary and Spitzberg, 1993), its compensatory capabilities may be limited both in 'strength' and in time. As a consequence, prolonged periods of perceived social isolation may reduce the usefulness of television in addition to further increasing distress levels. Indeed, a number of studies have found severe and chronic loneliness to be related to the derivation of fewer gratifications from television and specifically to less use of television for social compensation, with severely lonely people developing a passive viewing style instead, involving the use of television merely out of habit or to pass the time (Finn and Gorr, 1988; Perse and Rubin, 1990). Second, in the same line of thought, the long-term effect of companionship viewing on distress should be investigated. Even though the cross-sectional analyses calculated in the present study indicate a negative relationship between both concepts, it may be that companionship viewing provides short-term relief from feeling lonely, and as such may prove beneficial on long-term distress levels. Therefore, the present research topic would greatly benefit from longitudinal research designs, allowing both hypotheses to be tested.

Furthermore, given the importance of distress levels, the relationships in the model presented here should become weaker over time. Research studying reactions to criminal victimization has indicated that most victims show significant improvement in distress levels in the nine months following the event (Norris and Kaniasty, 1994). Consequently, as distress levels decrease over time, both actual and perceived social resources will be replenished, and the need for television to compensate for social deprivation should diminish. Once more, testing this hypothesis requires longitudinal research.

Nevertheless, even the results of the present study, based on crosssectional data, may contribute to greater insight into the roots of television viewing behavior. Furthermore, it may have the merit of bringing an omnipresent but overlooked aspect of everyday life - television viewing - to the attention of victimology research.

\section{Notes}

1. In Flanders, police officers are legally bound to offer assistance from a delegate of the Victim Support Unit (VSU) to people who report having become victim of a crime involving direct contact with the perpetrator or violation of the home. If this offer is accepted, the VSU contacts the victim within five days of being notified.

2. A total of $2.6 \%$ were victims or next of kin of victims of (attempted) murder/ manslaughter; $5.4 \%$ were rape victims; $4 \%$ victims of indecent assault; $10.2 \%$ do- 
mestic assault victims; $21.9 \%$ non-domestic assault victims; $14.4 \%$ stalking victims; $17.6 \%$ robbery victims, and $20.5 \%$ burglary victims. The remaining $3.4 \%$ were victims of other types of crime (e. g., false allegations, destruction of property, etc.).

3. Sample item depression: "Feeling lonely"; sample item distrust: "The feeling that most people are not to be trusted"; sample item hostility: "Getting often involved in quarrels".

4. This item read "Other people seldom ask me to do things together".

\section{References}

Aish, A. M. and Jöreskog, K. G. (1990). A panel model for political efficacy and responsiveness: An application of LISREL 7 with weighted least squares. Quality and Quantity, 24(4), 405-426.

Arrindell, W. A. and Ettema, J. H. M. (1986). Klachtenlijst (SCL-90) [List of Complaints (SCL-90)]. Lisse: Swets and Zeitlinger.

Austin, B. (1985). Loneliness and use of six mass media among college students. Psychological Reports, 56, 323-327.

Bard, M. and Sangrey, D. (1986). The Crime Victim's Book. New York: Brunner/Mazel.

Barrera, M. (1986). Distinctions between social support concepts, measures and models. American Journal of Community Psychology, 14, 413-445.

Browne, M. W. and Cudeck, R. (1993). Alternative ways of assessing model fit. In K. A. Bollen and J. S. Lang (Eds.), Testing structural equation models (pp. 136162). London: Sage.

Canary, D. J. and Spitzberg, B. H. (1993). Loneliness and media gratification. Communication Research, 20, 800-821.

Coates, D., Wortman, C. B., and Abbey, A. (1979). Reactions to victims. In I. H. Frieze, D. Bar-Tal, and J. S. Carroll (Eds.), New approaches to social problems: Applications of attribution theory (pp. 21-52). San Francisco, CA: Jossey-Bass.

Cohen, S., and Hoberman, H. (1983). Positive events and social supports as buffers of life change stress. Journal of Applied Social Psychology, 13, 99-125.

Cohen, S., Mermelstein, R., Kamarck, T., and Hoberman, H. (1985). Measuring the functional components of social support. In I. G. Sarason and B. R. Sarason (Eds.), Social support: Theory, research and application (pp. 73-94). Dordrecht: Martinus Nijhoff.

Cohen, S. and Wills, J. A. (1985). Stress, social support, and the buffering hypothesis. Psychological Bulletin, 98, 310-352.

Crane, P. A. and Constantino, R. E. (2003). Use of the Interpersonal Support Evaluation List (ISEL) to guide intervention development with women experiencing abuse. Issues in Mental Health Nursing, 24(5), 523-541.

Creamer, M., Burgess, P., Buckingham, W., and Pattison, P. (1993). Posttrauma reactions following a multiple shooting: A retrospective study and methodological inquiry. In J. P. Wilson and B. Raphael (Eds.), International Handbook of Traumatic Stress Syndromes (pp. 201-212). New York: Plenum.

Davis, M. H. and Kraus, L. A. (1989). Social contact, loneliness, and mass media use: A test of two hypotheses. Journal of Applied Social Psychology, 19(13), 1100-1124.

Denkers, A. J. M. and Winkel, F. W. (1998). Crime victims' well-being and fear in a prospective and longitudinal study. International Review of Victimology, 5, 141162.

Dittmar, M. L. (1994). Relations among depression, gender, and television viewing of college students. Journal of Social Behavior and Personality, 9, 317-328. 
Dohrenwend, B. S. (1978). Social status and responsibility for stressful life events. In C. D. Spielberger and I. G. Sarason (Eds.), Stress and anxiety (Vol. 5, pp. 2544). New York: Wiley.

Finn, S. and Gorr, M. B. (1988). Social isolation and social support as correlates of television viewing motivations. Communication Research, 15, 135-158.

Fischer, C. T. and Wertz, F. J. (1979). Empirical phenomenological analyses of being criminally victimized. In A. Giorgi, R. Knowles, and D. L. Smith (Eds.), Duquesne studies in phenomenological psychology (Vol. 3, pp. 135-158). Pittsburgh, PA: Duquesne University Press.

Frieze, I. H. and Bookwala, J. (1996). Coping with unusual stressors: Criminal victimization. In M. Zeidner and N. S. Endler (Eds.), Handbook of coping:Theory, research, applications (pp. 303-321). New York: Wiley.

Frieze, I. H., Hymer, S., and Greenberg, M. S. (1987). Describing the crime victim: Psychological reactions to victimization. Professional Psychology: Research and Practice, 18(4), 299-315.

Gabor, T. and Normandeau, A. (1989). Armed robbery: Highlights of a Canadian study. Canadian Police College Journal, 13(4), 273-282.

Geckova, A., Van Dijk, J. P., Stewart, R., Groothoff, J. W., and Post, D. (2003). Influence of social support on health among gender and socio-economic groups of adolescents. European Journal of Public Health, 13(1), 44-50.

Gibbs, M. (1980). Social class, mental disorder and the implications for community psychology. In M. S. Gibbs, J. R. Lachenmeyer, and J. Sigal (Eds.), Community psychology: Theoretical and empirical approach (pp. 173-205). New York: Gardner.

Gleser, G. C., Green, B. L., and Winget, C. N. (1981). Prolonged psychosocial effects of disaster: A study of Buffalo Creek. New York: Academic Press.

Hanson, R. F., Kilpatrick, D. G., Falsetti, A. S., and Resnick, H. S. (1995). Violent crime and mental health. In J. R. Freedy and S. E. Hobfoll (Eds.), Traumatic stress: From theory to practice (pp. 129-161). New York: Plenum Press.

Harrison, C. A. and Kinner, S. A. (1998). Correlates of psychological distress following armed robbery. Journal of Traumatic Stress, 11(4), 787-798.

Helgeson, V. S. (1993). Two important distinctions in social support: Kind of support and perceived versus received. Journal of Applied Social Psychology, 23, 825-845.

Herbert, T. B. and Dunkel-Schetter, C. (1992). Negative social reactions to victims: An overview of responses and their determinants. In L. Montada, S. H. Filipp, and M. J. Lerner (Eds.), Life crises and experiences of loss in adulthood (pp. 497518). Hillsdale, NJ: Lawrence Erlbaum.

Hobfoll, S. E. (1988). The ecology of stress. Washington, DC: Hemisphere.

Hoover, S., Skuja, A., and Cosper, J. (1979). Correlates of college students' loneliness. Psychological Reports, 44, 1116.

Janoff-Bulman, R. (1989). Assumptive worlds and the stress of traumatic events: Applications of the schema construct. Social Cognition, 7, 113-136.

Janoff-Bulman, R. (1992). Shattered assumptions. New York: Free Press.

Kamphuis, J. H. and Emmelkamp, P. M. G. (1998). Crime-related trauma: Psychological distress in victims of bank robbery. Journal of Anxiety Disorders, 12(3), 199-208.

Kaniasty, K. and Norris, F. H. (1992). Social support and victims of crime: Matching events, support, and outcome. American Journal of Community Psychology, 20(2), $211-241$.

Katz, E., Blumler, J. G., and Gurevitch, M. (1974). Utilization of mass communication by the individual. In J. G. Blumler and E. Katz (Eds.), The uses of mass communications: Current perspectives on gratifications research (pp. 19-32). Beverly Hills, CA: Sage. 
Kleinke, C. L. (1988). The depression coping questionnaire. Journal of Clinical Psychology, 44, 516-526.

Krupnick, J. (1980). Brief psychotherapy with victims of violent crime. Victimology: An International Journal, 5(2-4), 347-354.

Lepore, S. J., Evans, G. W., and Schneider, M. L. (1991). Dynamic role of social support in the link between chronic stress and psychological distress. Journal of Personality and Social Psychology, 61, 899-909.

Lerner, M. J. (1970). The desire for justice and reactions to victims. Social psychological studies of some antecedents and consequences. In J. Macaulay and L. Berkowitz (Eds.), Altruism and helping behavior (pp.205-229). New York: Academic Press.

Leymann, H. (1985). Somatic and psychological symptoms after the experience of life threatening events: A profile analysis. Victimology: An International Journal, 10, $512-538$.

Mahon, N. E. and Yarcheski, A. (2001). Outcomes of depression in early adolescents. Western Journal of Nursing Research, 23(4), 360-375.

McQuail, D. (1997). Mass communication theory. An introduction. London: Sage.

Mohr, D. C., Classen, C., and Barrera, M. (2004). The relationship between social support, depression and treatment for depression in people with multiple sclerosis. Psychological Medicine, 34(3), 533-541.

Norris, F. H. and Kaniasty, K. (1994). Psychological distress following criminal victimization in the general population: Cross-sectional, longitudinal, and prospective analyses. Journal of Consulting and Clinical Psychology, 62(1), 111-123.

Norris, F. H. and Kaniasty, K. (1996). Received and perceived social support in times of stress: A test of the social support deterioration deterrence model. Journal of Personality and Social Psychology, 71, 498-511.

Peirce, R. S., Frone, M. R., Russel, M., Cooper, M. L., and Mudar, P. (2000) A longitudinal model of social contact, social support, depression, and alcohol use. Health Psychology, 19, 28-38.

Perlman, D., Gerson, A., and Spinner, B. (1978). Loneliness among senior citizens: An empirical report. Essence, 2, 239-248.

Perloff, L. S. (1983). Perceptions of vulnerability to victimization. Journal of Social Issues, 39(2), 41-62.

Perloff, R. M., Quarles, R. C., and Drutz, M. (1983). Loneliness, depression and the use of television. Journalism Quarterly, 60(2), 352-356.

Perse, E. and Rubin, A. (1990). Chronic loneliness and television use. Journal of Broadcasting and Electronic Media, 34(1), 37-53.

Potts, R. and Sanchez, D. (1994). Television viewing and depression: No news is good news. Journal of Broadcasting and Electronic Media, 38(1), 79-90.

Quittner, A. L., Glueckauf, R. L., and Jackson, D. N. (1990). Chronic parenting stress: Moderating vs. mediating effects of social support. Journal of Personality and Social Psychology, 59, 1266-1278.

Regehr, C., Hemsworth, D., and Hill, J. (2001). Individual predictors of traumatic response: A structural equation model. Canadian Journal of Psychiatry, 46, 74-79.

Roe, K. (2000). Socio-economic status and children's television use. Communications: The European Journal of Communication Research, 25(2), 3-18.

Roe, K., Eggermont, S., and Minnebo, J. (2001). Media use and academic achievement: Which effects? Communications: The European Journal of Communication Research, 26(1), 9-14.

Rubin, A. M. (1981). An examination of television viewing motives. Communication Research, 8, 141-165.

Rubin, A. M. (1983). Television uses and gratifications: The interactions of viewing patterns and motivations. Journal of Broadcasting, 27, 37-51. 
Rubin, A. M. (1984). Ritualized and instrumental television viewing. Journal of Communication, 34(3), 67-77.

Rubin, A. M., Perse, E. M., and Powel, R. A. (1985). Loneliness, parasocial interaction, and local television news viewing. Human Communication Research, 12, $155-180$.

Silver, R. C., Wortman, C. B., and Crofton, C. (1990). The role of coping in support provision: The self-presentational dilemma of victims of life crises. In B. R. Sarason, I. G. Sarason, and G. R. Pierce (Eds.), Social support: An interactional view (pp. 397-426). New York: Wiley.

Turner-Cobb, J. M., Sephton, S. E., Koopman, C., Blake-Mortimer, J., and Spiegel, D. (2000). Social support and salivary cortisol in women with metastatic breast cancer. Psychosomatic Medicine, 62, 337-345.

Wethington, E. and Kessler, R. C. (1986). Perceived support, received support, and adjustment to stressful life events. Journal of Health and Social Behavior, 27, $78-89$.

Wirtz, P. W. and Harrell, A. V. (1987). Victim and crime characteristics, coping responses, and short- and long-term recovery from victimization. Journal of Consulting and Clinical Psychology, 55(6), 866-871.

Wortman, C. B. and Lehman, D. (1985). Reactions to victims of life crises: Support attempts that fail. In I. G. Sarason and B. R. Sarason (Eds.), Social support: Theory, research, and applications (pp. 463-489). Dordrecht: Martinus Nijhoff.

Yap, M. and Devilly, G. J. (2004). The role of perceived social support in crime victimization. Clinical Psychology Review, 24, 1-14. 